\title{
Classic of Mountains and Seas and the Origin of White Jade Worship: On the Myths of the Yellow Emperor's Eating Jade and Queen Mother of the West's Presenting the White Jade Ring
}

\author{
YE Shu-xian \\ Shanghai Jiaotong University, Shanghai, China
}

\author{
LIU Wan-er \\ Beijing Institute of Technology, Beijing, China
}

\begin{abstract}
The white jade worship, born in the Shang and Zhou Dynasties, brought about a "Protestant Revolution" in the development history of Chinese jade mythology, which had deep influence on the nation's ideology and material production in the following 3,000 years. The myths of the Yellow Emperor's eating the white jade cream and the Queen Mother of the West living in Kunlun Jade Mountain, as recorded in Classic of Mountains and Seas, are mythological imaginations of the historical reality that the jades were spread from the West to the East and recreated by people living in the early state of the Central Plains. All such motifs, no matter the white jade cream that produced black jades, the Yellow Emperor's planting the jade flowers, the Kunlun Jade Mountains (the Mountain of Jades) where the Queen Mother of the West lives or the Jade Lake, clearly show Chinese indigenous worship for the white jades. Scholars like Su Xuelin and Ling Chunsheng think that Queen Mother of the West is the goddess of the moon that originated from the old West Asian civilization. However, such idea is full of contradictions and flaws after the discovery of Chinese unique worship for white jades and the holy mountain of Kunlun. The book Classic of Mountains and Seas, with records of 140 mountains that produce jades and 16 mountains that produce white jades, can be the white jade worshippers' bible to explore the holy material resources.

Keywords: jade mythology, white jade worship, the Yellow Emperor's eating jade cream, the Queen Mother of the West's presenting the white jade ring
\end{abstract}

Since the eastward transmission of Western sciences, mythology has often been regarded, similar to the fairy tales, as fictional literary works under the frame of modern academic system. In current college education, mythology courses are only taught to students majoring in folk literature in Chinese language and literature department, so the mainstream of domestic research on mythology is from the perspective of literature or folk literature. In recent years, with the popularity of interdisciplinary research, a trend of studying mythology from the perspective of religious belief and ideology also came into being. Due to this, myths are regarded as the prototype of the whole culture including the humanities, history and philosophy, not only of the literature, which expands and changes the research pattern of mythology. In this paper, I focus my attention on two important mythological images - the Yellow Emperor and the Queen Mother of the West — that fully represent

YE Shu-xian, Chair Professor, Shanghai Jiaotong University. Director and Professor of Comparative Literature, Chinese Academy of Social Sciences, Editor in Chief of "The Series of Anthropological Explanation of Chinese Classics". His research field covers Chinese Literary Anthropology, Cross-culture research, Chinese classical culture and comparative literature.

LIU Wan-er, Graduate of Beijing Institute of Technology. 
Chinese cultural belief of jade, to reveal the non-fiction content hiding behind the literary appearances, i.e., to explore the hiding reality of history and idea history behind the fantastic literary images, analyze and unveil the rise of white jade worship, which is one significant "Protestant Revolution" in Eastern Asian 8,000-year-old jade culture, so that we can have an overview of the deep influence it has on post-the-Western-Zhou-Dynasty Chinese civilization, and illustrate its psychological role in building the nation's worship of jade and economic role in promoting the development of jade article industry at that time.

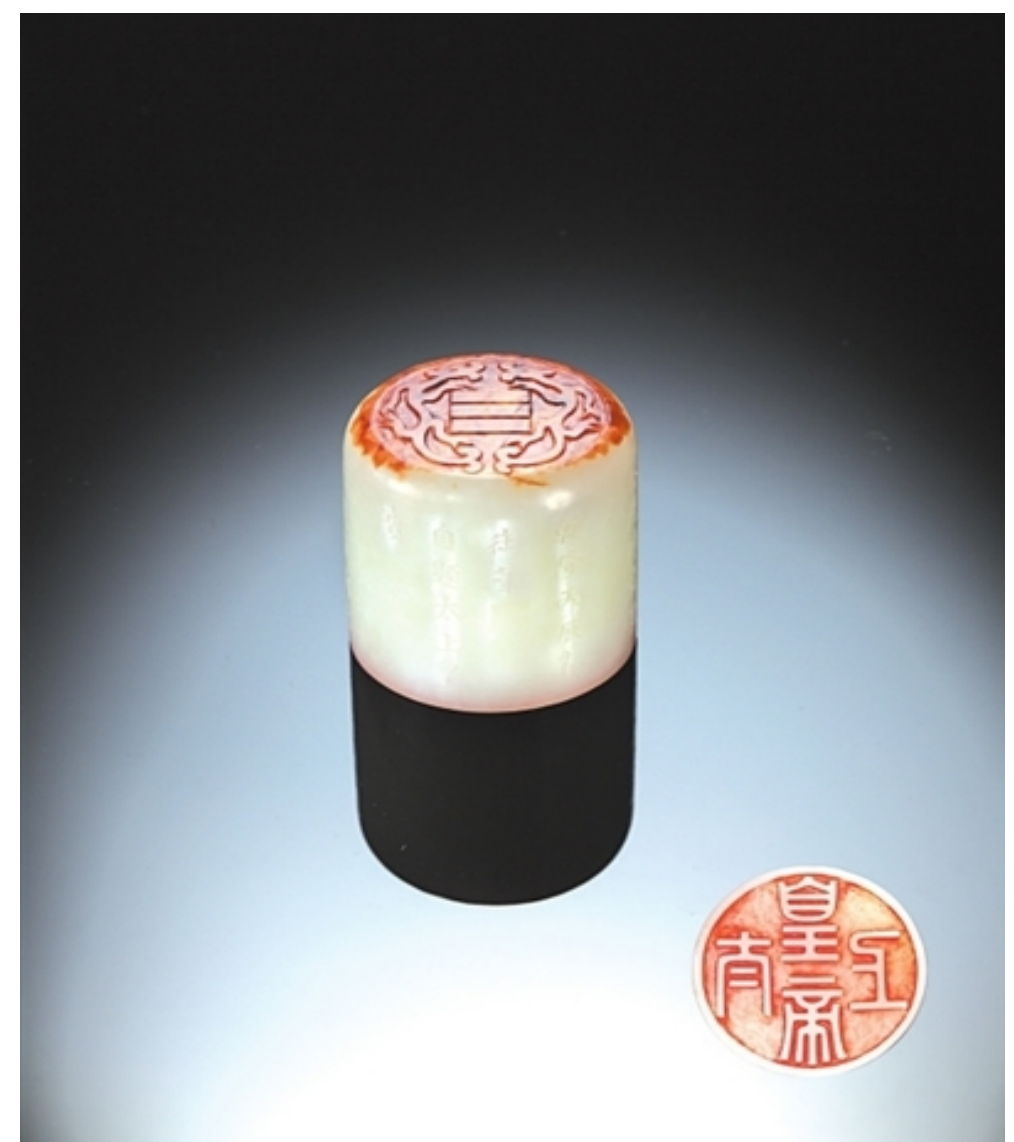

Figure 1. On December 8, 2011, a round white jade seal of the 60th year of Qianlong Emperor's reign broke the world record of jade article auction. Its hammer price is 161 million Hong Kong dollars.

\section{Chapter 1 The Jade Ring and the Myth of Its Origin}

In Baopuzi: the Way of the Ruler, Ge Hong talked about the ideal regime of the ancient times, which was often accompanied with various magical propitious portents. For example: "a spiritual bird is presented to the Emperor's at the red hall, and a jade ring is paid as a tribute to the Emperor." ${ }^{\text {.1 }}$ The spiritual bird refers to the white pheasant Yueshang presented to King Wu of Zhou when the King sent armed forces to punish King Zhou of Shang; and the jade ring refers to the white jade ring the Queen Mother of the West presented to Emperor Shun, the legendary monarch of ancient China. Since the Bamboo Annals, this ring has been named as the jade ring, the white ring, or sometimes the white jade. The pheasant is the wild chicken, whose males are in colorful

\footnotetext{
${ }^{1}$ Ge Hong, Part One of Yang Zhaoming's Index to the Outer Chapters of Baopuzi, Shanghai: Zhonghua Book Company, 1991, p. 223.
} 
feathers while females in taupe color. A while pheasant is rare to see, so the ancient people regarded it as spiritual bird, which is as precious as the valuable and rare white jade ring presented by the Queen Mother of the West. The term "Xi Ji (西极, meaning: the utmost west)" first appeared in Chu Ci: Li Sao: "the setting sun arrives at Xi Ji," which was annotated by Wang Yi as "the setting stops at the utmost west of the earth." Besides the four utmosts (the utmost east, west, north and south), there are also four waste lands as recorded in Erya: Shidi (Erya, the oldest surviving Chinese dictionary written in Han Dynasty), i.e., "Huzhu (解竹, literal meaning: lonely bamboos), Beihu (北户, literal meaning: north-facing door), Xiwangmu (西王母, literal meaning: Queen Mother of the West) and Rixia (日下, literal meaning: under the sun)”. Gu Pu annotated as: "all these four lands are very faraway states." Huzhu is in the north, Beihu in the south, Xiwangmu in the west and Rixia in the east. They are all desolate states which are next to the utmost." ${ }^{2}$ The four waste lands are four states near the four utmosts, and Xiwangmu is name of a state in the west. Earlier than this, in Western Han Dynasty, Huainanzi: Forms of Earth locates the State of Xiwangmu at: "Xiwangmu is along the Liu Sha (流沙, literal meaning: quicksand) River." Shang Shu: Tribute of Yu mentioned that, Liu Sha is located at the He Li (合黎) mountains, in the middle part of the Hexi Corridor: "Yu led the Ruo River to He Li, where it flew into the Liu Sha River." The upper part of Ruo River is the Shan Dan River in Gansu, while its lower part is named as the Heihe River which is the combination of Shan Dan River and Gan Zhou River, and renamed as Erginar River when it flows into the Inner Mongolia. Classic of Mountains and Seas: Classic of the Great Wilderness: West thought that Ruo River is at the foot of Kunlun Mountain, "at the food of Kunlun Mountain lies the deep pool of Ruo River." In Records of the Grand Historian: Treatise on the Dayuan, Sima Qian said: "according to the story told by the old Anxi people, there are Ruo River and Xiwangmu in Tiaozhi State." If what the story told is true, i.e., the Ruo River is a river in Tiaozhi State, it should be in current Central or Western Asia. In Book of the Later Han: Biographies of the Western Regions-Daqin, Fan Ye said: "in Daqin, there are Ruo River and Liu Sha River, which are close to where Xiwangmu (Queen Mother of the West lives)." All these possible locations are at the far west regions, some even in the Central and Western Asia. In Book of Han: Treatise on Geography, Part 2, Ban Gu also put Ruo River and Kunlun Mountain together, which is much closer to the Central Plains, i.e., in Qinghai Province: "in Jincheng County ... close to where the Qiang people lives." Original note: "in the west, there is Xudi Lake, Ruo River and Kunlun Temple." Erya: Explaining Earth also talked about the beauty of different places: the beauty of the east is the medicine, the witch, and Xun Yu Qi (珣玗琪, a kind of jade) of Lv Mountain; the beauty of the north west is the Qiu Lin Lang Gan (璆琳琅玕, beautiful jade with the shape of balls) of the Kunlun Mountain. Guo Pu annotated "Xun Yu Qi" as "a kind of jade", which actually is nowadays Xiuyan Jade of Liaoning; he annotated "Qiu Lin" as "beautiful jade" and "Lang Gan" as "with similar shape to balls". However, his illustration, being amphibolous, can only be used for reference. In fact, "Qiu Lin" and "Lang Gan" can be interpreted as a special term of Kunlun Mountain's Hetian Jade.

The previous literature told us that, in the national's opinion, the world's most beautiful jade came from the utmost west borders of the west regions, whose exact location must be somewhere in the great plateau west to the Central Plains, being very remote and out of ordinary men's reach. This place is often related to Kunlun, the mountain of myths, and Xiwangmu, the ancestor of immortals, like a trinity. Thus, the beautiful jade,

\footnotetext{
${ }^{2}$ Xing Bing, "Annotations to Erya", Annotations to the 13 Classics (Ruan Yuan, Ed.), Shanghai: Zhonghua Book Company, 1980, p. 2616.
} 
secular article produced in Kunlun Mountain of Tian State, is deified. Viewed from the myth of Xiwangmu, this goddess does not only own the supreme white jade in the utmost west, but also has the only elixir of life in the world. Comparing the two, the implied connection between the white jade and the elixir of life can be seen. From the perspective of mythological symbolism, the Jade Ring made from white jade produced in the utmost west, represents, on one hand, a peaceful and prosperous world with fair and clear politics which is accepted by the heaven of gods; on the other hand, human beings' dream for immortality.

The idea of Yin-Yang and Five Elements came into being in the Warring States Period. The five spatial places in the world are matched with the Five Elements and five colors, to realize the re-coding the mythological symbols of cosmology: the east is match with Wood and Cyan, the south with Fire and Red, the west with Metal and White, and the North with Water and Black. ${ }^{3}$ Accordingly, the national rituals dominated by the philosophy of Five Elements were also recoded, year after year operating regularly under the logics of four seasons. For example, in the months of summer, "the Emperor should sleep in the Zong Zhang Zuo Ge (总 章左个, meaning: southerly west room), take Rong Lu (戎路, meaning: the chariot), ride the white Tuo (骆), wear white clothes, adorn himself with white jades, eat sesame and dogs, and use weapons that is sharp and long." Annotation said: "Zong Zhang Zuo Ge refers to the bedroom located at the southerly west. Rong Lu refers to the chariot similar to that of Zhou Dynasty and decorated with white. Luo is the white horse that has black mane, and sesame, with patterns on it, belongs to Metal. Dogs are also animals being to Metal. Weapons that are sharp and long resembles the hidden harmful metal weapons." The west and the autumn are thus connected to the White and the Metal, forming a unit of symbolism and an inseparable coding system of classification. Accordingly, the authority also rearrange the jade rituals into "Liu Qi (六器, meaning: six vessles)" to match with the six spatial directions, i.e., the sky, the earth, the west, the east, the north and the south. Like what said in Rites of Zhou: Officials of Spring: Dazongbo (大宗伯, the head of the Officials of Spring):

Make Six Vessels with jades, to worship the heaven, the earth, the west, the east, the north and the south; worship the heaven with blue Bi (璧, a piece of jade with a hole in the center), worship the earth with yellow Zong (琮, a long hollow piece of jade with rectangular sides), worship the east with green Gui (圭, an elongated pointed tablet of jade held in the hands by ancient rulers on ceremonial occasions), worship the south with red Zhang (璋, an jade article with the shape of half Gui), worship the west with white Hu (琥, tiger-shape jade) and worship the north with black Huang (璜, semi-annular jade pendant). ${ }^{5}$

Zheng Xuan annotated as: "when worshiping the gods, you should choose vessels with similar shapes: Bi is round as the sky; Cong is square, like the earth; Gui is long and sharp, like the new born things in spring; Zhang is half the shape of Gui, like the dying things in summer; Hu is as majestic as the autumn; Huang is half the shape of $\mathrm{Bi}$, like the dormant winter, with nothing on the earth and they only appear at noon." Jia Gongyan annotated as: "they say 'Hu is as majestic as the autumn' because Hu has the shape of a tiger, belonging to the West, so it is as majestic as the autumn." In Compendium of Materia Medica: Metals and Stones (Part Two):

\footnotetext{
${ }^{3}$ Pang Pu, "On Five Elements", One Divided into Three: Research On and Interpretation of Traditional Chinese Ideas, Shenzhen: Haitian Publishing House, 1995, pp. 114-139. See also my works: Chinese Mythological Philosophy, Beijing: China Social Sciences Press, 1992, pp. 59-99, 166-176.

4 "Proceedings of Government in the Different Months", Book of Rites. See also: Kong Yingda et al. "Annotations to Book of Rites". Annotations to the 13 Classics (Ruan Yuan, Ed.), Shanghai: Zhonghua Book Company, 1980, p. 1373.

5 Jia Gongyan et al. "Annotations to Rites of Zhou”, Annotations to the 13 Classics (Ruan Yuan, Ed.), Shanghai: Zhonghua Book Company, 1980, p.762.
} 
Jades, Li Shizhen said: "according to old rites, black Gui, blue Bi, yellow Cong, red Zhang, white Hu and black Huang are used respectively to represent the sky, the earth, and four seasons." What needs to be mentioned is, Rites of Zhou used to be thought as a book describing the rites of Western Zhou Dynasty. However, modern scholars confirmed that the book was written during the transitional period of the Warring States and Western Han Dynasty, so what the Six Vessels system reflects are not the rites of Western Zhou Dynasty, but the Five Elements philosophy and the jade rites of Han Dynasty.

\section{Chapter 2 Why Dragon King of the East Sea Craves a White Jade Bed}

In Chinese civilization, the white jade is thought as articles of supreme preciousness. In the fourth chapter of A Dream of Red Mansions, a sentence is used to describe how rich the family of Wang Xifeng is: "the East Sea lacks a white jade bed, so the Dragon King came to ask Duke of Jinling's help." Why does the East Sea lack white jade bed? Because the white jades used to make the bed is produced in the west regions, west to the Central Plains, which is very far away from the East Sea which is east to the Central Plains. Only rich families, like the rulers or kinsmen of the emperor or empress, have the power and advantages in transporting and owning such rare resources in the large territory. So, even the Dragon King of the East Sea, a deity, also needs to ask the help of the King of Jinling, an immortal, who stocks rich white jades, so that he can realize the luxurious dream of owning a white jade bed.

Since ancient times, the white jade has not only been high officials or royals' luxury to show off, but also a symbol of one's status. Take the belt hook made of white jades as an example. In Story of the Embroidered Jacket: the Jacket to Protect Her Beloved from the Coldness written by Xu Lin of Ming Dynasty, the hero said: "once, I also wore ... hat of horse hair, belt hook of white jade, balls of ambers, coat of ramie silk and leather boots." The jade belt hood is a luxury unique to Chinese civilization, and that made of white jade is especially precious. Cao Yan, the father of Cao Xueqin, once wrote a poem name as See the Moon at the Yellow River and Show It to Ziyou (Ziyou, the style name of Cao Yan's brother) when he was appreciating the moon at the bank of the Yellow River. In the poem, he said "only this white jade belt hook can stretch forward to the source of Kunlun", which can be interpreted as a pun. Why such a white jade belt hook "can stretch forward to the source of Kunlun"?



Figure 2. Photo of jade Xuanji (璇现, according to Confucius, Xuanji is an instrument to watch the stars), taken in Shanghai Museum. 
Firstly, Cao Yan thought of the white jade belt hook he himself as wearing on the condition that he was looking at the moon in the sky. Such association is not his personal imagination or creation, but a common metaphor expression in the literary history - the shining moon in the sky looks like the white jade vessel in secular world that reflects white light. For example, in the poem Walking Under the Moon in Gulang, Li Bai said: "when I was young, I didn't know the moon, so I called it as a white jade plate." In his poem Feelings of Looking at the Moon in the Mid-Autumn Day, Wu Weiye of Qing Dynasty said: "I didn't realize the wisdom of waxing and waning until in my late years, I started to worry about the white jade plate." Now that the full moon shining white light makes people think of white jade plate, the slim crescent naturally makes people think of the white jade belt hook. Both the origin place of white jade and the source of the Yellow River are thought to be a large mountain in the western border of Chinese states - the Kunlun Mountain, thus Cao Yan connected two irrelevant natural objects - the moon and the Yellow River. He thought the moon as white jade, which also originates from Kunlun Mountain. He also imagined the Yellow River which flew to the east also originates there. The imagination about the Yellow River is thought to be something of "mythological geography", which is typical Chinese ancient geographical philosophy, i.e., mythological imaginations guide the real geographical thinking and the real geographical being is dominated and transformed by the imagined mythological concepts. The result is, the source of the Yellow River, which is in Qinghai Province, is imagined to be in the far western mountain, i.e., the Kunlun Mountain south to the Tarim Basin in Xinjiang Province. In The Waters of Lop Nor: Part One, Volume One of Records of Waters in the Western Regions, Xu Song, the historian of Qing Dynasty who specialized in the Western Regions, said: "Lop Nor is where the original source of the Yellow River stagnates and accumulates".

Here, Xu Song talked about the original source of the Yellow River, which was derived from the idea of "Yellow River's Double Sources", i.e. the Kunlun Mountain at Yutian, Xinjiang Province is the original source, which flew underneath from Kunlun to Lop Nor, and then comes out of the earth again when it arrived at Jishi Mountain (the second source) which was located at the border of Qinghai Province and Gansu Province. This theory solved the contradiction between "dredge the Yellow River at Jishi" in Shang Shu: Tribute of Yu and "the Yellow River originates from Kunlun" in Classic of Mountains and Seas, Records of the Grand Historian, Erya, etc. This theory solved the contradiction between "dredge the Yellow River at Jishi" in Shang Shu: Tribute of Yu and "the Yellow River originates from Kunlun" in Classic of Mountains and Seas, Records of the Grand Historian, Erya, etc." " Gu Pu of Jin Dynasty, who annotated Classic of Mountains and Seas, was unable to clarify which place "Wu Da (无达)" referred to, so he had to say that it was name of a mountain. This caused trouble for locating where the Kunlun Mountain is. Viewed from the textual context of Classic of the Mountains: West, the Kunlun Mountain is about 1,300 Lis away from the famous mountain which produces the most beautiful jades in the world, and about 800 Lis away from the Zhongshan Mountain. All these mountains are part of the generalized Kunlun Mountains, which, the same as Mount Tianshan and Qilian Mountain, are characterized with being high and steep, and covered with white snow. In the Western cultural, the national psychology of worshiping the white color is to some degree connected to such natural geographical environment and conditions. Chinese usually compare the high peaks which are covered with snow all year long as jade mountain or jade imperial peak, because the white snow and the white jade have similar colors.

The myth of the Queen Mother of the West's Presenting the White Jade Ring especially highlights the

${ }^{6}$ Yuan Ke, Collation and Annotation to Classic of Mountains and Seas, Shanghai: Shanghai Guji Publishing House, 1980, p. 47. 
connection between white jade worship and ancient mythological characters. The story, though being very simple, implies three cultural messages:

First, in the opinion of the people in the Central Plains, the origin place of white jades is the remote Western Regions, which are represented by the place where the Queen Mother of the West lives.

Second, the white jade is precious and rare, because it has something to do with the only secret of immortality which is owned by the Queen Mother of the West, which is the supreme dream of ordinary men.

Third, the Ring, being round in shape, implies the meaning of recycling which directs to limitless vastness. The implication of the jade ring unique to Chinese culture is friendly communication, in which courtesy demands reciprocity. In Xunzi: Dalue, Xunzi said: "Hire a person with Gui (珪, meaning: an elongated pointed tablet of jade held in the hands by ancient rulers on ceremonial occasions), ask a scholar's help with Bi, send for a person with Yuan (瑗, meaning: a jade ring with a big hole and small brim), break with a person with Jue (玦, meaning: penannular jade ring), refuse to break with a person with Huan (环, a kind of jade ring).” Five jade sacrificial vessels have different meanings and functions. Among them, the fourth one (Jue) and the fifth one (Huan) are opposite and supplementary. In Guangyun, the authors said: "when an official is exiled to the frontier, if what he gets from the Emperor is Huan, it means that he can come back to the court; if what he gets is Jue, it means he won't be back any more." Na Zhiliang explained as: both jade Huan and jade Jue can be used as official tallies. Obviously, the exiled officials wanted very much the government's pardon, allowing them to go back home. Instead of any documents, either of two articles-Huan or Jue will be sent as an announcement by the government. Huan has the same pronunciation as another Huan (还, meaning: return), symbolizing the permit of returning home. Jue has the same pronunciation as another Jue (绝, meaning: refuse), symbolizing that there is no pardon. ${ }^{7}$ However, different from the general meaning of jade ring in Chinese culture, the white jade ring the Queen Mother of the West presented to the ruler of the Central Plains mainly conveyed the meaning of friendly communication.

As for the origin of Xiwangmu (Queen Mother of the West) and the Kunlun myth, some modern scholars (represented by Sun Xuelin, Ding Shan, Du Erwei, Xue Gaoruan and Ling Chunsheng) influenced by foreign scholars like Hirth think that Xiwangmu is the goddess of the moon in the ancient civilization of the Tigris and Euphrates Valley in the Western Asia. When introduced to the Central Plains, it was translated into three Chinese characters, i.e. Xi (西, meaning: west) Wang (王, meaning: monarch) Mu (母, meaning: mother). People at that time were not clear about how Chinese jade culture passed on from the prehistoric period to the Shang and Zhou Dynasties. Things are different now: numerous unearthed jade articles show us that, the jade rituals since Western Zhou Dynasty can't be without white jades and greenish white jades. But these jades are rare in the Central Plains, so the transportation of jades from the west to the east turned more and more fierce since the Xia, Shang and Zhou Dynasties, which supplied Hetian jades of Xinjiang (with white jade as the most precious) to the rulers of China. Based on this, we can see that the myth of Xiwangmu's presenting the white jade ring to the Emperor has its root in the reality, instead of being totally imaginative in cultures with no white jade worship.

\section{Chapter 3 The Prototype of White Jade Worship: The Yellow Emperor's Eating Jade Cream}

Viewing the mineral resources in different places as recorded in Classic of Mountains and Seas from the

${ }^{7}$ Na Zhiliang, Pictorial Illustrations to Ancient Chinese Jades, Taipei: SMC Publishing Inc., 1990, p. 178. 
perspective of religious worship, we can interpret the real idea history in relevant mythical narrations. The Classic of Mountains and Seas talked about more than 140 mountains that produced jades, 16 of which produced white jades. And among these 16 white-jade-producing mountains, the 7th one, i.e., the Mi Shan Mountain (崚（密）山) was the one described in most details. Mi Shan was in the same volume as Kunlun: the volume of Classic of the Mountains: West.

Another 420 Lis to the northwest lies a mountain name as Mi Shan. On it, most trees are red woods, with round leaves, red trunks, yellow followers and red fruits which taste like sugar. Once eating the fruits, people won't feel hungry any more. Dan River came out of the Cen Mountain, and went west into the Cheng Pool. In the river grew many white jades. So did some jade cream whose origin was boiling. The Yellow Emperor fed on this cream, thus produced black jades. Watered by jade cream for five years, the Dan plant became colorless and smelt sweet. So the Yellow Emperor took jade flowers of Mi Shan and planted them on the southern side of the Zhong Mountain. Beautiful jades were pretty good, solid and exquisite, and also shined lights. They shined five colors, and with the gentle lustre, the hard stones looked soft. Since the ghosts and gods fed on jades, by wearing them, gentlemen could be protected from ominous things. It was 460 Lis from the Mi Shan Mountain to the Zhong Mountain, which were full of waters. In the waters, there were rare birds, weird beasts and strange fishes, all of which were rarities. ${ }^{8}$

Of the whole Classic of Mountains and Seas, this passage is the best part in describing and worshiping jades because of four reasons. First, what it describes is a special kind of white jade. Second, the white jade can magically transform and can produce and be produced. It turns into jade cream, and then white jade cream produces black jade. This fully demonstrates the secret of Yin-Yang change. Third, the jade cream is nutritious, being able to be the food of the Yellow Emperor who was the Chinese ancestral god; also, it is the food of ghosts and gods. This means, the jade is eatable.

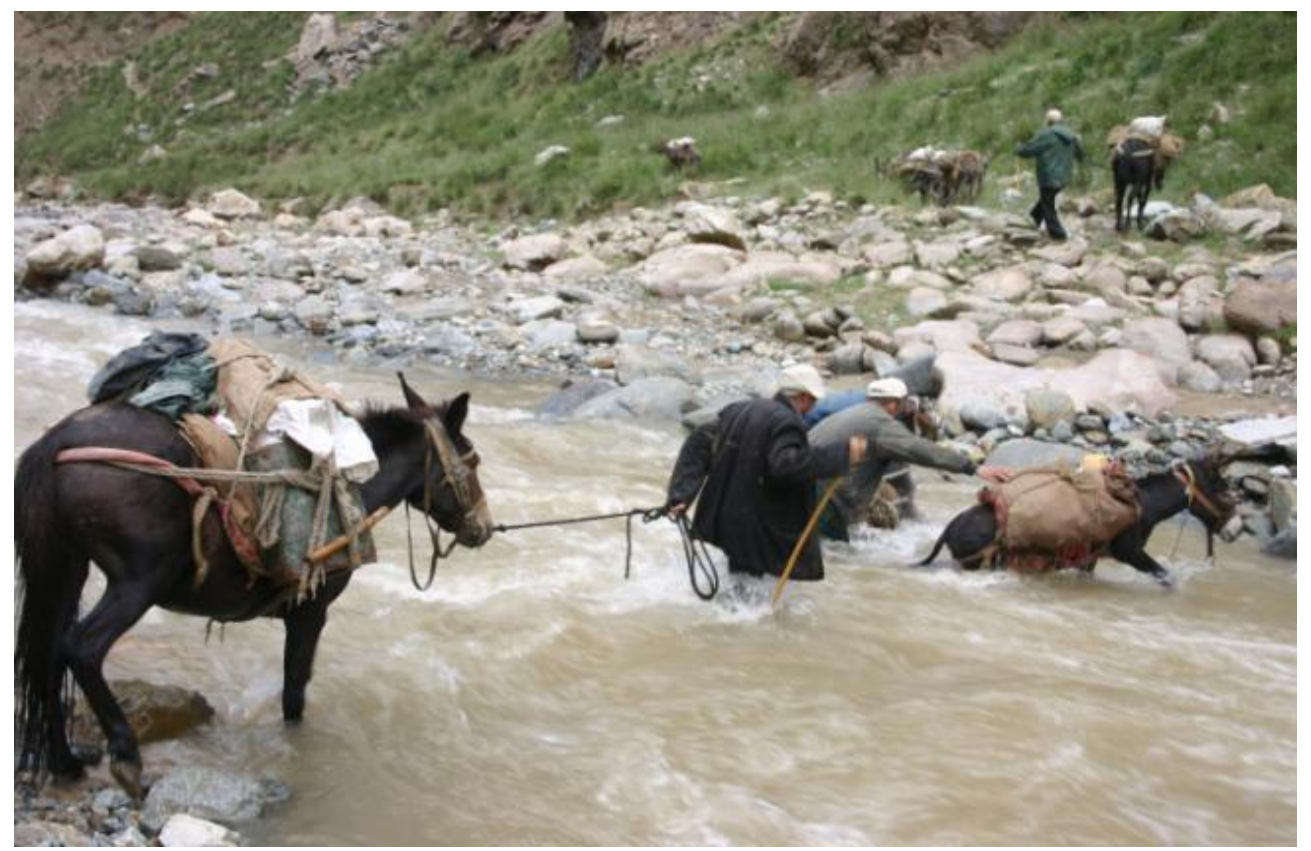

Figure 3. A scene at the source of "transporting jades from the west to the east", i.e., the Kunlun Mountain at Hetian. The photo was taken by Wu Xinhua in 2012, a researcher at Xinjiang Archeology Institution.

\footnotetext{
${ }^{8}$ Yuan Ke, Collation and Annotation to Classic of Mountains and Seas, Shanghai: Shanghai Guji Publishing House, 1980, p. 41.
} 
The physical change bought by the jade cream is achieving immortality, to guarantee the eternity of the god's life. This is enough to initiate the ruler's imagination and dream. Four, it refers to the imagination about the planting and reproduction of this special white jade: So the Yellow Emperor took jade flowers of Mi Shan and planted them on the southern side of the Zhong Mountain. What was produced were named as Jin Yu (瑾瑜, meaning: beautiful jade), whose qualities are describes as "solid and exquisite", which are in accordance with two nowadays indicators in testing the jades: high hardness and great density. Beautiful jades were pretty good, solid and exquisite, and also shined lights, and Guo Pu annotated as "the jade is smooth and thick." It is as moist we say today. Being moist and shining, this is how the ancient people described the physical characteristics of Hetian jade at Kunlun Mountain — shining as oil, which is the "oil quality" of jade. The contrarian indicator is "water quality", i.e., being dry and rough, which will greatly influence the feeling quality of jades. Without experience Chinese intuitive feeling of the jades, people will have difficulty in understanding this description about these qualities of the supreme jade materials. Such description of jade resource seems to be ordinary; however, from the viewpoint of cultural anthropology, it requires the internal perspective of jade culture holder, i.e., "from the perspective of an aborigine", to grasp the theme in the context. Such description will become unreasonable anecdote when detached from the special context of Chinese jade culture.

In ancient literature, no other jades, except the white jades, were such magically described. It can be speculated that, in the ancient people's imagination, the white jades have greater power in communicating with the gods and spirituals than jades of other colors. As for why white jades are connected with such mysterious and magical imaginations, we can refer to the expressions in classic literature (such as the shining objects in the sky - the sun and the moon, are both compared to white jades) to get that idea of unification of man and god.

Since the myth of the Yellow Emperor is very popular, he is worshiped as the national ancestor by Chinese people. So the myth of his eating the white jade cream also has a deep influence on Chinese civilization, especially on the naming of food. When it comes to white food (from the white drinking liquid to the white jelly tofu), Chinese often have beautiful imaginations, such as jade juices, brocade clothes and jade food. In Essays of Old Man at Jie An: Tofu Poem, Li Xu of Ming Dynasty expressed the wonderful feeling when eating tofu in a witty tone: "I labored to sharpen a Kunwu sword, and used it to cut the white jade into chunks. I fried them to satisfy my mouth, not afraid of my old teeth at all.” Tofu, as being a special food of Chinese people, has no equivalent in English, so it was translated by transliteration. This shows the locality of tofu. To make tofu, first grind the soybeans into milk, then boil the milk and add some gypsum or bittern to congeal it into a chunk, at last pressed to lose some water, it will turn solid. The process of making tofu also conforms to the imagination of "jade cream". Li Shizhen, the master of pharmacy in Ming Dynasty, thought that tofu dates back to Western Han Dynasty. In its works Compendium of Materia Medica: Crops-Part Four: Tofu, he said: "the method of making tofu originated from Liu An, Huainan Duke of Han. All kinds of black soya beans, soybeans, white peas, muddy soybeans, peas and mung beans can be used to make tofu." Liu An was the author of the famous works of ancient philosophers other than those of Confucius-Huainanzi. To some degree, the myth of the Yellow Emperor's eating white jade cream drove people's experiments in making it. This is inseparable with the eating jade philosophy under the jade religious beliefs since the ancient times. Even in Ming Dynasty, when the crop - corn originally grown by American Indians was introduced into China, it was given the name of Yu Shu Shu (玉蜀秘, literal meaning: jade Sorghum bicolor) or Yu Mi (玉米, literal 
meaning: jade rice). From the prehistoric period to Ming Dynasty, we can see how long-lasting the influence of jade eating philosophy is. In his works Annotation to Idioms: On Plants, Sun Jinbiao said: "According to Hai Men Wu Zhi ... rice which has shells are also called Sorghum bicolor. In Compendium of Materia Medica, it is called as jade Sorghum bicolor. Nowadays, people usually call it as jade rice." The association of food and beautiful jades is deeply rooted in the great tradition of jade culture, which gradually gives birth to new symbol coding behaviors.

The phase jade food became common in the literature of many scholars and intellectuals. In Shang Shu: Great Plan of Jizi, the author described the privileges of the monarch as: "only the monarch can enjoy happiness, only the monarch can act as a tyrant, and only the monarch can eat jade food. There is no official who enjoys happiness, acts as a tyrant, or eats jade food." Kong Chuan said: "only the monarch has the privilege of acting as a tyrant, enjoying happiness, and eating delicious food." The later generation use the idiom of "acting as a tyrant and enjoying happiness" to mean holding power over someone's life and property. In his commentary, Sun Xingyan said: "what is means is that, the monarch should perfect his nature, so that he can be moderate and control his temper so that he can perform his privilege in enjoying happiness and acting as a tyrant." In Shi Gu, the author said: "it talks about the monarch. And the jade food is delicious food." In Book of Wei: Biography of Chang Jing, the author said: "behaving like this, your house will be safe even you have gorgeous pavilions and gold doors; the life of wonderful clothes and jade food can keep you fit." In his poem Feelings of Reading in a Rainy Autumn Night, Lu You said: "the officials in charge of the monarch's dining recommend jade food, while the ordinary people only have delicious cress." In Cautious about Marriage: Love Visits written, a drama by $\mathrm{Li} \mathrm{Yu}$, a character said: "you hold yourself much too aloof. You abandoned your house of red doors and jade food, and came to such a shabby valley to ask for bamboo mat and gourd ladle." This is a metaphor unique to Chinese, from the jade cream of the Yellow Emperor, to the jade food of all monarchs and the wonderful clothes and jade food or the red doors and jade food of high officials and noble lords. When examining its origin and inheritance, the myth of the Yellow Emperor's eating jade cream in Classic of Mountains and Seas is obviously the prototype of these narrations and imaginations.

Emperor Wu of Han who was obsessed about achieving immortality through eating jade food valued very much the jades collected from the faraway Western Regions. In Records of the Grand Historian: Treatise on the Dayuan, there is description about the Emperor examined the ancient books by himself to name the mountains in the west which produced jades. It is very likely that Emperor Wu of Han took Classic of Mountains and Seas as reference to name "Kunlun" when he was inspecting the samples of beautiful jade brought to the court by messengers of Xinjiang.

\section{Chapter 4 Classic of Mountains and Seas and the White Jade Worship in Tale of King Mu, Son of Heaven}

In Chu Ci: Nine Songs: The Lady of the Xiang, Qu Yuan said: "take white jades to press the seats, and spread the Folium Pyrrosiae to make the room full of fragrance." We can know that, since Eastern Zhou Dynasty, the white jades have stood out of jades of various colors and became the subject praised by poets.

\footnotetext{
9 Sun Xingyan, Annotations to and Comments on Old and New Articles of Shang Shu, Shanghai: Zhonghua Book Company, 1986, p. 309 .
} 


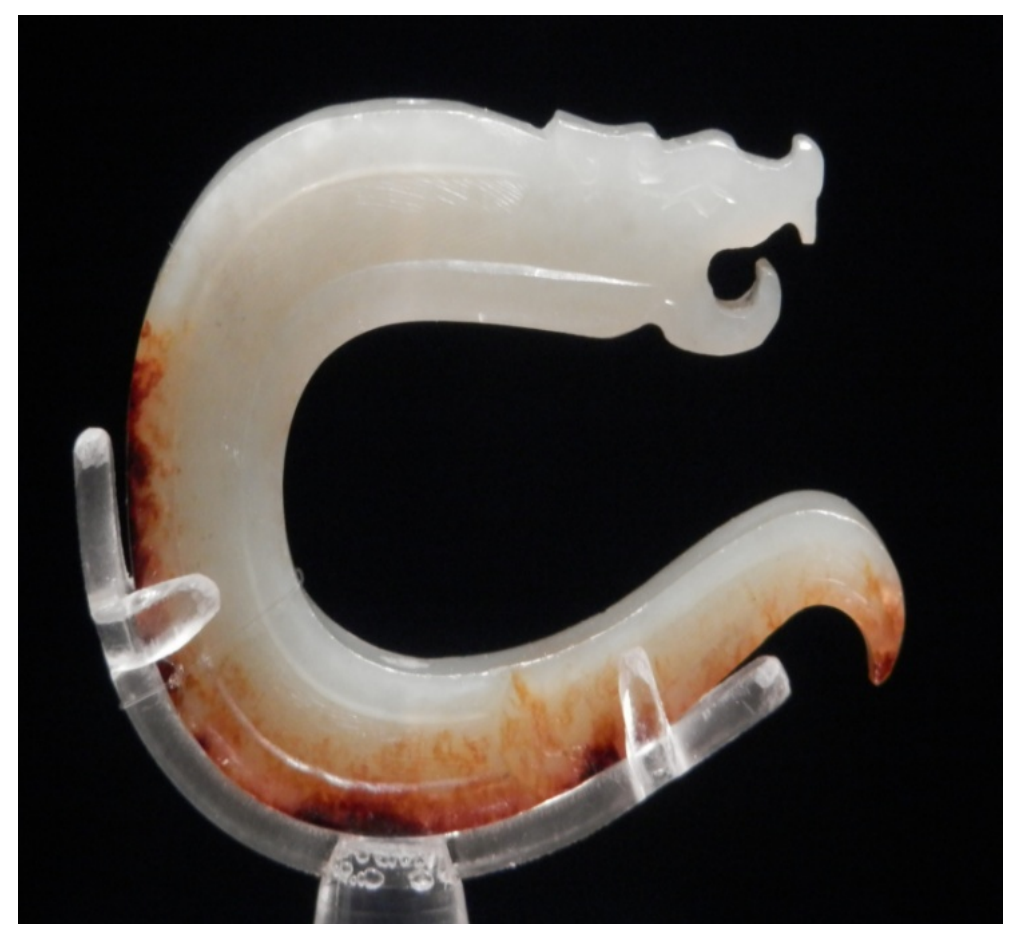

Figure 4. Photo of the white jade dragon of the Warring States Period which was unearthed in Jinzhou, Hubei Province. The photo is taken in Jinzhou Museum.

The charm of white jade resulted from a conceptual revolution of jade beliefs which was the first time in history, i.e., the worship of jades of any color to the worship of jade of pure white. I call this big revolution of mythological concepts as the "Protestant Revolution" of the jade religion. The background of this revolution was, Hetian jades of Kunlun Mountain in Xinjiang was transported into the Central Plains on a large scale, which started the new tradition of transporting jades from the west to the east which lasted for three to four thousand years. Since perfect white jades can only be found in Hetian jades of Xinjiang, the white jade worship didn't appear in thousands of years' prehistoric jade culture. It was obvious, at that time there was yet no cultural revolution of "transporting jades from the west to the east", so no white jade materials was available in producing jade sacrificial vessels or in the system of jade rituals. Once the rulers of the central plains found and started to use the white jade, the subject of worship in their ideology witnessed significant changes. Viewed from this, in Classic of Mountains and Seas, one of the 16 listed mountains that produced white jades was named as "White Jade Mountain". This is no coincidence. We can speculate this book is the secret treasure map of those devout believers after the Protestant Revolution (the white jade worship) of Chinese jade religion came into being.

Reading the old pre-Qin book Classic of Mountains and Seas which had great influence on A Dream of Red Mansions while keeping white jade worship in mind, the reader will soon realize that the author, for a special purpose, mentioned whether a mountain produced white jades when he introduced each of the 140 jade-producing mountains. Such mentions appeared more than 16 times. Is this coincidence? According to modern mining knowledge, white-jade-producing mountains in China are very rare, impossible to amount to 16 in number. However, more than 2,000 years ago, Classic of Mountains and Seas said this with so much certainty, paying great attention on the specialties of each place: first recording whether it produces jades, then talking about whether it has white jades. What was the author's purpose? 
In other words, the jade and the white jade are differentiated holy articles. In Tale of King $M u$, Son of Heaven which came into being in the Warring States period, jades of different colors were also emphasized. For example, according to narration in Volume 2: King Mu visited the Yellow Emperor's Palace at Kunlun Mountain, and worshiped Kunlun with sacrifices; later, he went further north and stayed at a place named as Zhu Ze (珠泽, literal meaning: jade pond ), by whose bank King Mu fished and said: “Zhu Ze's water spreads an area of $30 \mathrm{Li}^{2}$. ." The following narration immediately after this one is:

Then $\square$ white jade/s was/were presented.

Here, something is missing. The subject who presented the white jade was not mentioned. With only the predicate and the object, we are not clear that who presented this white jade. Also the number was missing, so we don't know how many jades were presented. According to the annotations by Guo Pu and Hong Yixuan of Qing Dynasty, Shi Wu Ji Yuan thought that "people living in Zhu Ze region presented white jade(s) material to King Mu." ${ }^{10}$ The subject is added, so we know that it was the local people of Zhu Ze who presented white jade material to King Mu. After that, more things were presented to him.

So, 300 horses and 3000 cattle and sheep were presented to King Mu. ${ }^{11}$

From inscriptions on bronze objects that recorded how the Emperor of Western Zhou awarded his officials, we can see that the jade and the horse were the two most important treasures of that time and they were in the charge of the supreme ruler, which made them the key object in constructing the power network and the clearly stratified society under the enfeoffment system of Western Zhou. Among all colors of jades transported from the west to the east, the white jades, because of its rareness, are more precious than others.

According to statistics in Classic of Mountains and Seas, 16 of the more than 140 jade-producing mountains produce white jades, with the other more than 120 mountains only produce jades of other colors, and white jades only account for $11 \%$ of the total jades. The 16 white-jade-producing mountains are: Yuanyi Mountain, Jiwei Mountain, Kuishan Mountain, Dashi Mountain, Lutai Mountain, Xiaoci Mountain, Mishan Mountain, Leyou Moutain, Youshou Mountain, Jinggu Mountain, Zhongqu Mountain, Niaoshutongxue Mountain, Baisha Mountain, Yizhu Mountain, Geshan Mountain and Xiongshan Mountain. Besides, there is another mountain whose name is "White Jade Mountain". As for the geographic positions of these mountains as recorded in the Classic of Mountains and Seas: three of them are included in Classic of the Mountains: South, nine in Classic of the Mountains: West, one in Classic of the Mountains: North, zero in Classic of the Mountains: East and three in Classic of the Mountains: Central. So, geographically, 56\% of white-jade-producing mountains gather in the region recorded by Classic of the Mountains: West, more than the 44\% which totals those in the Classic of the Mountains: South, Classic of the Mountains: North, Classic of the Mountains: East and Classic of the Mountains: Central. The Classic of Mountains and Seas was regarded as the treasure house of ancient ides in the great tradition, from which we can see that, for generations of ancient Chinese, their geographical and mining knowledge system made them firmly believe that the mountains in China's west plateau are the main place producing white jades. With the popularity of Thousand Character Classic and other readings which tell that "jade comes from Kunlun", people gradually think that the Kunlun Mountain is the only place that produces white jades and other places are forgotten.

Till the 20th century, the Hetian jades of Xinjiang became deteriorated. So people started to look for and

\footnotetext{
${ }^{10}$ Guo Pu, Classic of Mountains and Seas Collated and Annotated by Guo Pu, Changsha: Yuelu Publishing House, 1992 , p. 217.

${ }^{11}$ Guo Pu, Classic of Mountains and Seas Collated and Annotated by Guo Pu, Changsha: Yuelu Publishing House, 1992, p. 212.
} 
mine substitutes for Hetian jades. Then, the other two white-jade-producing places are found: Baikal in Russia and Golmud in Qinghai, China. In the jade industry, white jades from Baikal are called "Russian materials", and those from Golmud "Qinghai materials" (or Kunlun jades). Compared with Heitian white jades of Xinjiang, the Russian materials are whiter in color, but a little worse in oil quality; while, the Qinghai material are grayish white in color, have hidden water lines, better translucency and much worse in oil quality.

In 2014, I joined in a cultural delegation of the Jade Road to Gansu Province. We found a 23-kilometer-long mountain which produces shining white jades at the northern part of Datou Mountain which is located in Guazhou, Gansu Province, close to Xinjiang. The sampling report tells that the Mohs' hardness of jades here is six, with all major indexes equal or close to the Hetian jades of Xinjiang. The only difference is that there is visible difference in their white colors. The Hetian white jades are usually slightly greenish; however, the white jades of the Datou Mountain are slightly yellowish. This means: in the western plateau of China, there are multiple places that produce white jades. It remains a mystery how much unknown jade materials are mined from here. The 16 white-jade-producing mountains recorded in the Classic of Mountains and Seas can't be fabricated in the study, but based on real investigation or sampling.

Besides the white jades, in Classic of Mountains and Seas, another 11 mountains are recorded as producing blue and green jades, and another eight mountains as producing water jades, i.e. crystals; and in the chapter of Classic of Mountains: Central, five mountains are recorded as producing "White Min (珢)". Min refers to beautiful stones that are similar to jades. In Xunzi: Lawful Behaviors, the author said: "so, although Min is colorful, it's no match for the white and shining jade." Here, the grades of Min and white jade are differentiated. In Book of Han: Sima Xiangru (Part 1), the author said: “the stones there include Chi Yu (赤于, literal meaning: red jades), Mei Gui (玫瑰, literal meaning: a kind of beautiful jades), Lin (琳, literal meaning: a kind of beautiful jades) and Kun $\mathrm{Wu}$ (昆吾, literal meaning: name of a kind of stones which are inferior to jades)". In Yan Shigu's annotations, he cited Zhang Ji as: "Lin is a kind of jade. And Min is stone that is inferior to jades." Though the ancient people prefer white jades to Min, they also paid attention to white Min as substitution of white jades under the condition that white jade materials were rare. If not so, Min won't be listed by Classic of the Mountains and Seas as one of the special resources. This also proves the white jade worship in the mind of the authors of Classic of Mountains and Seas.

It's also worth noting that, when Classic of Mountains and Seas talks about the Yizhu Mountain, it first says that on the Mountain, gold and jades are produced, and then says that in the rivers under the mountain, white jades are produced. Here, jades and white jades are illustrated in parallel, similar to the expression that "white horses are not horses". Why so? Do white jades have special characteristics? From this, we can know that, by particularly noting the places producing white jades, Classic of Mountains and Seas implies a social values system and mythological beliefs and concepts. The concrete situation of these concepts has long been forgotten. From the details in the jade ritual when King of Mu, Son of Heaven, met with Queen Mother of the West, we can slightly feel what's behind them.

On a lucky day of Jiazi Year ${ }^{12}$, the King of Mu visited the Queen Mother of the West as a guest. He held a white Gui (圭, an elongated pointed tablet of jade held in the hands by ancient rulers on ceremonial occasions) and a black Bi (璧, a piece of jade with a hole in the center) to meet her, and present a hundred Chun of

\footnotetext{
12 Jiazi (甲子) Year: The first year of Chinese sexagenary cycle, also known as Stems-and-Branches, which is a cycle of 60 terms used for recording days or years.
} 
flowered silk bands to her. Three hundred Chun of silk bands, the Queen Mother of the West worshiped again and again and then accepted them. ${ }^{13}$

$\mathrm{Gu} \mathrm{Pu}$ annotated as: "Chun is the name of cloth." King Mu of Western Zhou, who came from the Central Plains, called on the Queen Mother of the West, brought a large amount of silk-a hundred Chun of flowered silk bands and another three hundred Chun of a kind of silk products whose name is lost. In ancient times, one Chun means a segment of cloth and silk. For example, Chan-kuo ts'e: Strategies of Qin recorded that: "one thousand Chun of fine silk, one hundred pairs of white Bi (璧, a piece of jade with a hole in the center), and ten thousand Yi (溢, a unit of weigh used in ancient China, and 1 Yi equals to 1 or $1.2 \mathrm{~kg}$ ) of gold." Bao Biao annotated as: "Chun refers to four edges." Here, "hundred", "thousand" and "ten thousand" express the value of these things - the ranking shall be the white jade, the fine silk and the gold. From the number of each kind of gifts King Mu brought to the Queen Mother of the West, we can crudely infer the value or status of each kind. There are hundreds of silk products, but only one jade Bi and Jade Gui, and Bi is black or dark green while Gui is white. The contrast in color is very sharp. What concept is hidden behind this? The special combination and contrast of white Gui and black Bi demonstrates various mysterious imaginations, such as the round and the square, the black and the white, the sky and the earth, the Yin and the Yang, which is much food for thought, like saying something that's unsaid.

We can compare this with Mi Mountain as recorded in Classic of Mountains: West which describes the legendary story that the white jade can produce jade cream, and then the jade cream can produce black jade. In the variation and transformation of two colors, the transformation of Yin and Yang and the change of the universe are implied. In current jade circle, a kind of Hetian jades is called "Qing Hua jades (literally 'green-flowered jades')", which are in dark and light colors. Such comparison is connected with the two legendary images examined in this paper, i.e., the ancestral god (the Yellow Emperor) and the goddess named as "Queen Mother" (the Queen Mother of the West). Penetrating through the magic color in this myth narration, we can see the hidden message of reality - no matter the god or the goddess, the black or the white, the prototype of these myths' focus is the exclusive white jade produced in the west regions. A river at the foot of Kunlun Mountain which produces white jades is exactly named as "Bai Yu River (literally 'White Jade River')", and the river which produces green jades is named as "Lv Yu River (literally 'Green Jade River')".

According to the records in History of Five Dynasties: Yutian State:

In the third year of Tianfu Reign of Jin Dynasty, the emperor sent Zhang Kuangye and Gao Juhui as assistants to the local officials, to confer the title of "Dabao King of Yutian" on Li Shengtian. Juhui recorded that 1,300 $\mathrm{km}$ south to Yutian is a mountain named as Jade State, which is the very mountain Zhang Qian of Han saw when he had traveled to the origin of the Yellow River at Yutian and was said by Zhang as being rich with jades. The source of the Yellow River is three rivers at Yutian: the eastern one is White Jade River, the western one is Green Jade River, the westernmost one is Black Jade River. All the three rivers produce jades, but of different colors. Every autumn, when the rivers dry up, the King will get jades out of the waters. Only after that can the common people go get jades out of the waters. After Kuangye and other assistant came back to Jin, Shengtian sent the governor Liu Zaisheng to bring a thousand Jin (one Jin equals half a kilogram) of jades, jade seals and Xiang Mo Zhu (Anti-Evil Stick) to present them to the emperor.

\footnotetext{
${ }^{13}$ Guo Pu, Classic of Mountains and Seas: Tale of King Mu, Son of Heaven Collated and Annotated by Guo Pu, Changsha: Yuelu Publishing House, 1992, p. 223.
} 
Now that we find in reality the Kunlun Mountain which produces both the white jades and the black jades, the physical prototype of white Gui and black Bi is also found. From the King's monopolization of the jades, we can see why facilities like Yu Shi Zhang (Jade Stone Block) and Yu Men Guan (Jade Gate Pass) were built on the way to transfer such precious, rare materials from the remote West Regions to the Central Plains. They were just built to effectively ensure the smoothness of the jade road which represented the national benefits, so by that the form of taxation the emperor can gain strategic material, and meanwhile maximize his benefits.

In narration, the Yellow Emperor and the Queen Mother of the West seem to be independent and different. But viewing from the geological locations, they all lived in the holy Kunlun Mountain. They seem to be the holy men being together with the source of the Yellow River and the source of jades. What's different is that they have different identities: the male one is the ancestor of humans, and the female one is the ancestor of gods. Both the ancestor of humans and the ancestor of gods live in the same place, which is also the source of Chinese Mother River and the source of beautiful jades, so we can see that: the secrets of Kunlun myths are exactly the secrets of Chinese civilization.

Classic of Mountains and Seas: "Jade Mountain is where the Queen Mother of the West lives. $480 \mathrm{Li}$ (one Li equals half a kilometer) west to the Jade Mountain is a hill named as Xuanyuan." Huainanzi said: "The hill named as Xuanyuan is west to the Jade Mountain." According to Gao You's annotation: Xuanyuan is the alternative name of the Yellow Emperor. The Yellow Emperor's Palace starts from the Kunlun Mountain, as recorded in Tale of King Mu, Son of Heaven: the Son of Heaven ascended up the Kunlun Mountain to view the Yellow Emperor's Palace. He asked for jades and saw what they were like. As recorded in Classic of Mountains and Seas: So the Yellow Emperor took jade flowers of Mishan Mountain and planted them on the southern side of the Zhongshan Mountain. As recorded in Tai Bai Yin Jing: the Yellow Emperor used jades as weapons. Same information can be found in Yue Ju Shu. In Biography of Xuanyuan, the Yellow Emperor: at the beginning, the Yellow Emperor divided the state into divisions, then ordered the governors of hundreds of counties to entitle those who taught virtues to the people, first arrange Gui jade on the cattail mats ... to differentiate the central Chinese and the western tribes. So, the Yellow Emperor was the first Chinese who used jades. ${ }^{14}$

When Zhang Hongzhao identified the Yellow Emperor as the first jade user, China didn't yet have archeology. Nowadays, according to archeological findings, we know that the earliest jade use was in Xinglongwa Culture which dated back to 8,000 years ago. This is 3,000 years earlier than the age of the Yellow Emperor. From the myth of the Queen Mother of the West's Presenting the White Jade Ring in the age of the Yellow Emperor, we can see that the Yellow Emperor and the Queen Mother of the West are imagined as deities of the same era. Based on the white jade worship of the dynasties of the Central Plains, we can speculate the origin of the myth of the Yellow Emperor and the Queen Mother of the West as Shang and Zhou Dynasties which are 3000 years ago. The revolution of the jade religion brought by the white jades make the later rulers focus on the white jades and the places producing white jades. The 5th emperor of Western Zhou Dynasty, King Mu, went to meet the Queen Mother of the West at Kunlun was the symbolic incident to show the fixed white jade worship. After Western Zhou Dynasty, the white jade worship developed into the direction of immortality, which was the reason why the narration of Mishan Mountain appeared in Classic of Mountains and Seas: Classic of the Mountains: West: (in Mishan Mountain), there are many white jades. There is jade cream here whose origin was boiling, and the Yellow Emperor fed on this. Guo Pu cited He Tu Yu Ban and said:

${ }^{14}$ Zhang Hongzhao, The Elegance of Stones, Tianjin: Baihua Culture and Art Publishing House, 2010, p. 96. 
“"on the Shaoshishan Mountain, there is white jade cream. And once drank the cream, people will become immortal.' This is similar to the Mishan Mountain."15 The specialty of Mishan Mountain, the white jade cream has same mythological function as the specialty of Western Kunlun Mountain, the jade flowers (the flowers on the jade trees), i.e., the function of symbolizing immortality. As for this, Book of Han: Biography of Sima Xiangru cited from Da Ren Fu: "breathe the vapor of nights and eat the rosy glow of dawn, chew ganoderma flowers and eat some jade flowers." In Yan Shigu's annotations, he cited Zhang Ji as: "The jade tree grows at the bank of western river of Kunlun Mountain, with the perimeter of 300 Wei (1 Wei means the perimeter of two arms enclosed) and the height of ten thousand Ren (1 Ren means around 1.76 meters). The stamen or pistil of its flowers, being eaten, can make people immortal."

We can know that jade worship contains the old fantasy of immortalizing. The connection between white and dream of immortality can generate from the forever-shining stars - the sun, the moon and others. In his poem, Li Bai called the moon as "white jade plate", which vividly shows the metaphor of white jade in Chinese mythological thoughts. From the Yellow Emperor's eating jade cream to the Queen Mother of the West's presenting white jade ring, the protagonists are different in gender and identity, but what is the same is more important, i.e., the pursuit of spiritual values in jade worship and the ideal of regarding white jade as immortal and holy. The later generations usually say "Bai Bi Wu Xia" (flawless white jade, used to describe impeccable moral integrity of a man), which is the secular extension of the holy ideal. In the special cultural context of Chinese civilization, with the interaction of myths of man and jade, such thoughts and concepts came into being. On the premise of this, we can better understand the function of white jade at the Hongmen dinner (a dinner at Hongmen Where treachery—-murder of the invited guest—was planned) as described in Records of the Grand Historian and why the First Emperor of Qin chose a white jade — the jade of the He family to make the Imperial Jade Seal that passed from one dynasty to the next.

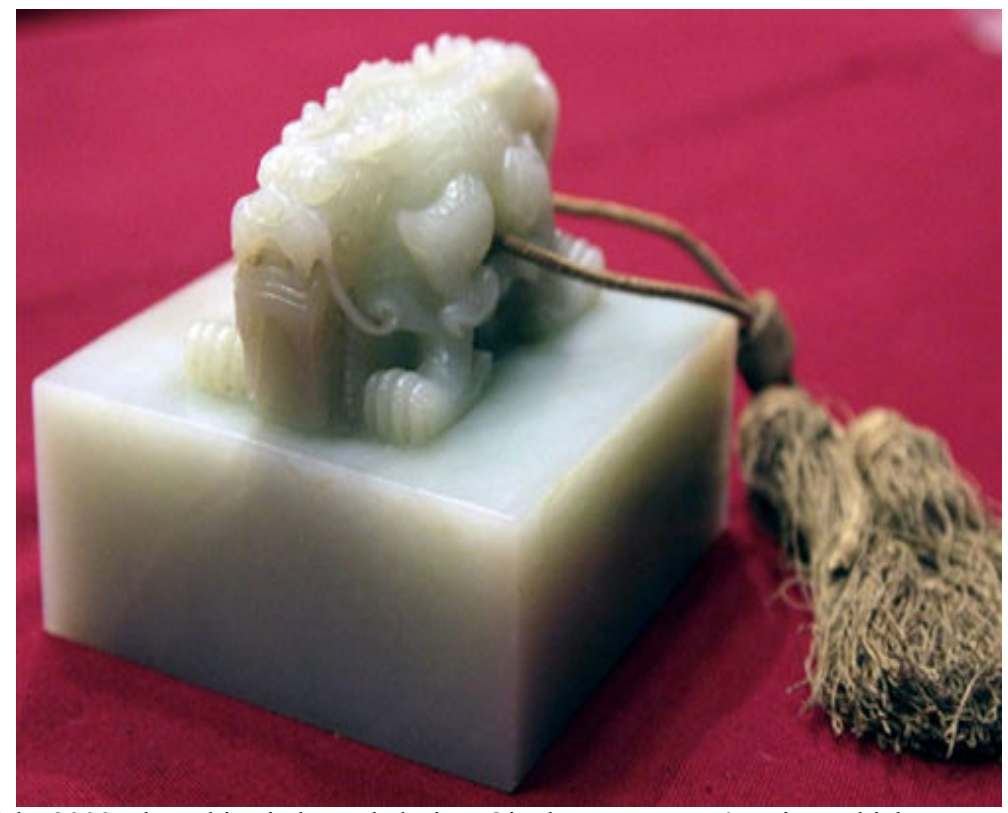

Figure 5. April 29th, 2009, the white jade seal during Qianlong Emperor's reign which was robbed from the Old Summer Palace by the Eight-Power Allied Forces (aggressive troops sent by Britain, the United States, Germany, France, tsarist Russia, Japan, Italy and Austria in 1900 to China) was sold by 1,680,000 Euros at the auction in Paris.

${ }^{15}$ Yuan Ke, Collation and Annotation to Classic of Mountains and Seas, Shanghai: Shanghai Guji Publishing House, 1980, p. 41. 


\section{Chapter 5 Classic of Mountains and Seas Is the Holy Bile of White Jade Worshippers}

As for how the book Classic of Mountains and Seas was made, there have been many disputes. Some say it was made in Xia Dynasty, some in Shang Dynasty, in Western Zhou Dynasty, Eastern Zhou Dynasty, Han Dynasty or others. According to nowadays unearthed antiques, we can roughly confirm that the white jade worship in states of Chinese civilization came up in Shang and Zhou Dynasties, and the large-scale use of white jade is a phenomenon after the middle period of Western Zhou Dynasty. Among the holy jades that symbolize the king's power as reflected in literature like Shang Shu: Testamentary Charge, we can see list of local jade materials including Yi Jade and Yue Jade, which are also great in number. So far, the white jade worship was still at the beginning stage, with its unique creeds and concepts not formed yet. If not, there wouldn't be so many local jades of multi colors that were also regarded as precious treasure of the royal family of Zhou Dynasty. The saying of "Kun Mountain Jade" began to become the nationals' common sense since the Warring States Period. So the old names- "Qiu Lin", "Lin Lang" and others are then replaced. That was why their meanings were not even known by the learned scholar Guo Pu of Jin Dynasty. Currently, Classic of Mountains and Seas is the only old book that recorded the white jade resource and its production areas in many details and in a comprehensive way. For this matter, its valuable meaning can only be known by white jade worshippers. In the early ideology of Chinese civilization, white jade is important with its double functions of being both material resource and spiritual worshipping object. With the unusual appearance of these mythological narrations, the reliable of relevant information in Classic of Mountains and Seas is shown by comparing with the inheritance vein of jade culture discovered by archeology. If taking the uniqueness as the judging standard, Classic of Mountains and Seas can be seen as the first holy book of the early white jade worshippers in Chinese civilization. Examining when the book came into being from the perspective of white jade worship, it should belong to Eastern Zhou Dynasty which followed Western Zhou Dynasty. Since it should have the material premise of quite active jade transportation from the west to east, it can't appear in Xia Dynasty and Shang Dynasty when the jade transportation from the west to east had just begun.

The myths of the Yellow Emperor's eating the white jade cream and the Queen Mother of the West living in Kunlun Jade Mountain, as recorded in Classic of Mountains and Seas, are recreations of mythological imaginations nourished by the historical reality in the early state of the Central Plains. Both the prototype and drive of such imaginations came from the worship of Hetian Jade, especially the white nephrite, by the state rulers in the Central Plains. All such mythological motifs, no matter the white jade cream that produced black jades, the Yellow Emperor's planting the jade flowers, the Kunlun Jade Mountains (the Mountain of Jades) where the Queen Mother of the West lives or the Jade Lake, typically show Chinese indigenous worship for the white jades. Scholars like Su Xuelin and Ling Chunsheng thinks that Xiwangmu (Queen Mother of the West) originated from the moon god of ancient western Asian civilization and is a Chinese translation through cultural transmission. Such idea was once popular, but also caused long-lasting arguments. Now, faced with unique Chinese white jade worshippers we restored, the idea that Xiwangmu came from foreign civilization exposes its flaws. 


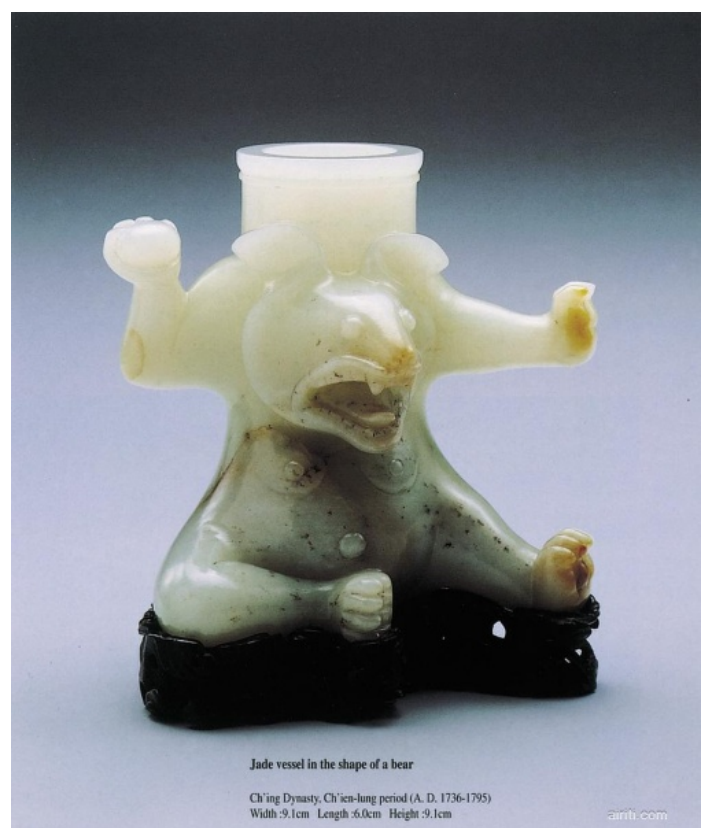

Figure 6. The white jade bear wine vessel during Qianlong's reign of Qing Dynasty, now stored in Taipei's National Palace Museum. 